\title{
Las verdades más incómodas del cambio climático no son climáticas
}

\author{
ROBERTO J. FERNÁNDEZ \\ Cátedra de Ecología e IFEVA, Facultad de Agronomía - Universidad de Buenos Aires, CONICET, Ciudad Autónoma de \\ Buenos Aires, Argentina.
}

\begin{abstract}
[Palabras clave: adaptación, cambio global, economía, energía, gases de efecto invernadero, globalización, huella ambiental, mitigación, pobreza, remediación]
\end{abstract}

[Keywords: adaptation, economics, energy, equity, environmental footprints, globalization, global change, greenhouse gases, mitigation, remediation]

El poder está en manos de quienes se encuentran cerca de las fuentes de incertidumbre. Michel Crozier (1922 - 2013)

\section{INTRODUCCIÓN}

El aumento de los gases de efecto invernadero (GEI) en la atmósfera es el más comentado - y uno de los más estudiados- de los impactos humanos sobre el planeta por ser motor del cambio climático y de su consecuencia más general y conocida: el calentamiento global. Hay consenso acerca de que estos cambios serán en su mayoría perjudiciales, y por lo tanto también hay muchos análisis sobre cómo evitarlos, o por lo menos atenuarlos. Está claro que las emisiones que resultan en los cambios de composición de GEI provienen de actividades humanas, en parte de la intensificación del uso de la tierra, pero, sobre todo, del uso de combustibles fósiles como carbón, gas y petróleo. Esta conexión entre clima y uso de energía lleva (al igual que la de biodiversidad vs. uso de la tierra) al más general y necesario de los debates ambientales: cómo resolver el aparente conflicto entre desarrollo económico y cuidado del ambiente.

La Convención Marco de las Naciones Unidas sobre el Cambio Climático (el tratado internacional más activo en temas ambientales) ya tiene más de 20 años, y la entrada en vigor del Protocolo de Kioto, fijando compromisos de reducción de las emisiones de GEI para los países que lo ratificaron, ocurrió hace casi diez. Los documentadísimos informes a la Convención por parte del Grupo

Editor asociado: Lucas Garibaldi
Intergubernamental de Expertos sobre el Cambio Climático (IPCC), que actualizan el estado del conocimiento y los avances hacia esas metas, muestran resultados poco alentadores. Pese a que los compromisos han sido vistos como demasiado modestos (poco más que un puñado de países europeos ha logrado cumplirlos), las últimas Conferencias de las Partes (COPs), aun teniendo en cuenta los recientes y esperanzadores anuncios de China y EEUU - los dos países con mayores emisiones-, han arribado a resultados muy pobres.

El propósito de este artículo es proponer varias lecciones que surgen de la corta historia de interacción entre ciencia y política internacional sobre cambio climático, y que creo importantes para la discusión de otros temas ambientales: I) no esperar a que aumenten las certezas científicas para decidir modos de acción, II) no ver los planes de "adaptación" (amortiguación de los efectos) o remediación de los posibles cambios climáticos como una confesión de fracaso acerca de las posibilidades de "mitigación" (reducción) de las emisiones, III) no interpretar la publicación de datos que no confirman nuestras expectativas o conveniencias como un ataque a nuestras convicciones, y IV) no apelar sólo a la responsabilidad individual, ya que es una vía injusta, además de poco práctica. 
Paul Krugman, Premio Nobel de Economía 2008, ha escrito recientemente que las dificultades de EEUU para actuar contra el cambio climático son, más que técnicas e incluso económicas, "una mezcla tóxica de ideología y anti-intelectualismo" (New York Times, 8 de junio de 2014). Una opinión diferente, pero que también enfatiza la importancia crucial de lo político-ideológico, es la de Martín Caparrós (2010): “...éste es un mundo tibio, que ve cómo millones de personas mueren de causas evitables sin preocuparse realmente, pero que por otro lado ha conseguido movilizar una enorme cantidad de recursos frente a la amenaza de entibiarse un par de grados más."

Aun estando convencido de que el cambio climático debe ocupar un lugar destacado en la agenda ambiental mundial, me parece que es sano detenerse a analizar los argumentos de quienes piensan que quizás no sea tan prioritario para el Sur como lo sugiere el grado de atención que se le brinda desde el Norte. Después de todo, la definición de qué constituye "un problema" es un ejercicio político de construcción social (Ingram et al. 2007), con la subjetividad de todo proceso basado en valores e intereses. Hacia el final del artículo, basándome en las cuatro lecciones listadas arriba, propongo dos vías por las que parte de los recursos y la atención dirigidos al cambio climático -independientemente de que los encontremos justificados o nopueden aprovecharse para reducir la injusticia que representan las desigualdades actuales en el consumo y el acceso a la educación y la salud. En este sentido, mi mensaje es que ya sabemos que existen intereses creados, y que hasta es posible que haya conspiraciones, pero éstos deberían ser tomados como datos, no como excusas.

Las ideas que siguen fueron motivadas por la lectura de tres libros: el ya citado Contra el Cambio, de Caparrós (2010), The Climate Fix, de Roger Pielke Jr. (2010) y Daños Colaterales, de Zygmunt Bauman (2011). Como muestran sus subtítulos (Tabla 1), ninguno de los tres fue escrito para ganar amigos. A su manera, cada uno nos enfrenta con varias verdades incómodas, no sólo como investigadores sino también como docentes y ciudadanos privilegiados en tanto profesionales universitarios. En la Tabla 1 se resumen sus principales mensajes relacionados con los temas aquí discutidos, y lo relevante de las historias de vida contrastantes de sus autores.
He introducido allí y en el resto del artículo, una docena de frases casi textuales de los tres libros, siempre mencionando al autor, pero sin incorporar la cita formal ni comillas para facilitar la lectura.

\section{CiEnCIA E INCERTIDUMBRE}

Los tres libros le asignan un papel importante a la incertidumbre en la que vivimos inmersos, y una de sus mayores coincidencias es que la situación no tenderá a mejorar al respecto (Tabla 1, fila I). Pielke desarrolla un ejemplo aleccionador del peligro que representa la sobre-simplificación de datos para forzar conclusiones, por más que se haga con las mejores intenciones. Cuenta cómo dos investigadores de la Universidad de Princeton (EEUU) publicaron un trabajo en el que intentaron mostrar que ya existían varias tecnologías para la provisión de energía, suficientemente bien probadas como para reemplazar las de origen fósil hasta por lo menos mitad de siglo (Pacala \& Socolow 2004). Como lo reconoció después Stephen Pacala, el objetivo del "paper" era eminentemente político: promover acciones contra el cambio climático por parte del gobierno norteamericano. Sin embargo, fue usado en un sentido totalmente inverso, para justificar la inutilidad de más inversión en tecnologías alternativas.

El principio precautorio puede ser paralizante si se interpreta como "primero comprendo, después actúo" (Jobbágy 2014). Por eso, parecería que tenemos que acostumbrarnos a que la incertidumbre no disminuirá, lo que para el cambio climático significa que no debemos dar por sentado que se cumplirán los objetivos de mitigación (i.e., caída de las emisiones de GEI), y simultáneamente trabajar sobre la adaptación de los sistemas socioecológicos a los efectos del cambio, aumentando su resiliencia y reduciendo su vulnerabilidad. Esto es lógico y prudente, en general, pero lo es más aun para un país como el nuestro, con menos de $1 \%$ de contribución a las emisiones globales (Australia, por ejemplo, con emisiones comparables, lo está haciendo de manera muy activa). Dadas no sólo las incertidumbres sino los hasta ahora pobres resultados de los esfuerzos de mitigación, tener un "Plan B" de adaptación parece recomendable, y no debiera ser visto como una confesión de derrota, ni implica renunciar a buscar, a la vez, mejores vías de mitigación. 
Tabla 1. Tres libros frecuentemente citados en este artículo y algunos de sus mensajes más relevantes. Se destacan los contrastantes orígenes generacionales, geográficos y académicos de sus autores. Los puntos I a IV son conclusiones propias y se desarrollan en el texto principal. Las cursivas marcan citas literales o ligeramente editadas. CC: cambio climático.

Table 1. Three books frequently cited in this article and some of their relevant messages. The contrasting generational, geographical and academic backgrounds of the three authors are highlighted. Points I to IV are own conclusions, developed in the main text. Italics mark verbatim (or slightly edited) quotations. CC: climate change.

\begin{tabular}{|c|c|c|c|}
\hline $\begin{array}{l}\text { Libro (año de } \\
\text { publicación) }\end{array}$ & $\begin{array}{l}\text { The Climate Fix; What Scientists } \\
\text { and Politicians Won"t Tell You } \\
\text { About Global Warming (2010) }\end{array}$ & $\begin{array}{l}\text { Contra el Cambio; un Hiperviaje } \\
\text { al Apocalipsis Climático (2010) }\end{array}$ & $\begin{array}{l}\text { Daños Colaterales; Desigualdades } \\
\text { Sociales en la Era Global (2011) }\end{array}$ \\
\hline $\begin{array}{l}\text { Autor, año y país } \\
\text { de nacimiento, } \\
\text { especialidad }\end{array}$ & $\begin{array}{l}\text { Roger PIELKE, Jr., EEUU, } \\
\text { 1968. Politólogo con formación } \\
\text { en matemática y análisis de } \\
\text { riesgo. Hijo del meteorólogo } \\
\text { homónimo (R.P., Sr.). }\end{array}$ & $\begin{array}{l}\text { Martín CAPARRÓS, } \\
\text { 1957, periodista y escritor } \\
\text { argentino. Estudió historia en } \\
\text { Francia, y también vivió en } \\
\text { España y EEUU. }\end{array}$ & $\begin{array}{l}\text { Zygmunt BAUMAN, Polonia, } \\
\text { 1925. Sociólogo, exiliado en } \\
\text { Inglaterra desde 1971. Conocido } \\
\text { por sus trabajos sobre } \\
\text { el Holocausto y la modernidad. }\end{array}$ \\
\hline $\begin{array}{l}\text { Reseña - altamente } \\
\text { selectiva }\end{array}$ & $\begin{array}{l}\text { Desde su privilegiada } \\
\text { perspectiva, formado en } \\
\text { ciencias sociales pero con } \\
\text { temprana experiencia de } \\
\text { trabajo en ciencias "duras", } \\
\text { hace un análisis muy } \\
\text { documentado y altamente } \\
\text { crítico del comportamiento } \\
\text { de todos los participantes del } \\
\text { debate del CC, tanto del IPCC } \\
\text { como de sus fustigadores. } \\
\text { Mark Sagoff http:// } \\
\text { issues.org/27-3/br_sagoff-2/ } \\
\text { sugirió que el término "fix" del } \\
\text { título está usado sin inocencia, } \\
\text { con la misma ambigüedad } \\
\text { que el de su traducción } \\
\text { castellana, "arreglo", } \\
\text { indicando que la politización } \\
\text { del CC llevó a una pérdida } \\
\text { de integridad en ambos } \\
\text { "bandos", que en muchos } \\
\text { casos presentaron información } \\
\text { intencionadamente sesgada. }\end{array}$ & $\begin{array}{l}\text { Producto de viajes y } \\
\text { entrevistas por encargo } \\
\text { del Fondo de las Naciones } \\
\text { Unidas para la Población. } \\
\text { Opina que el CC puede estar } \\
\text { siendo aprovechado desde el } \\
\text { Norte para obtener beneficios } \\
\text { económicos y políticos. } \\
\text { Sin negar la ciencia, propone } \\
\text { que el CC no es el problema } \\
\text { más serio que enfrentamos. } \\
\text { Por ej., ironiza: Señora } \\
\text { l Malamba, si por casualidad } \\
\text { consigue algo para comer, } \\
\text { cocínelo de forma que no moleste } \\
\text { a Gaia. } \\
\text { Equipara la militancia } \\
\text { ambientalista a una } \\
\text { religión, "la ecololó" (con } \\
\text { sus evangelistas, sacerdotes } \\
\text { y recaudadores). Sumo } \\
\text { sacerdote: James Lovelock. }\end{array}$ & $\begin{array}{l}\text { Compilación de conferencias } \\
\text { de } 2010-2011 \text {. No menciona } \\
\text { específicamente el CC, pero la } \\
\text { Introducción y los capítulos } \\
\text { sobre el Consumismo, y la } \\
\text { Desigualdad son altamente } \\
\text { relevantes para los temas } \\
\text { ambientales. } \\
\text { La economía y la cultura del } \\
\text { consumo determinan como } \\
\text { daño colateral la existencia de } \\
\text { marginados que carecen no sólo de } \\
\text { oportunidades inmediatas de paliar } \\
\text { su pobreza sino también de toda } \\
\text { perspectiva de superarla a futuro. } \\
\\
\text { Los problemas que nos resultan } \\
\text { más visibles y cercanos, } \\
\text { incluyendo los de inseguridad, } \\
\text { no tienen solución local, ya } \\
\text { que son daños colaterales de la } \\
\text { globalización... descoordinada, } \\
\text { descontrolada e impulsada por la } \\
\text { búsqueda de dividendos. }\end{array}$ \\
\hline
\end{tabular}

I.

La incertidumbre no es excusa para la inacción - si no lo es en otros campos ¿por qué debiera serlo en cuestiones ambientales?

\section{La ciencia es un proceso que}

constantemente genera nuevas preguntas. A los científicos se les exige certeza, y es un error responder, como a veces lo ha hecho en el IPCC, sobresimplificando los datos y forzando conclusiones.

\section{...derrumbadas las utopías} socialistas del siglo XX, el futuro aparece como una amenaza y no como una esperanza...

El rechazo de la certeza no consigue que la incertidumbre sea más tolerable.
Llama "líquidas" a las sociedades actuales, con relaciones personales y laborales ambivalentes, cambiantes y fluidas, más volátiles y menos previsibles que en el pasado, que era más "sólido".

Hay razones para sentir cada vez más incertidumbre = ignorancia + impotencia, como los personajes de la "Lotería de Babilonia", de Borges.

Pensar en atenuar los impactos Fuimos capaces de multiplicar derivados del CC no equivale el número de personas por 12 , y a una confesión de fracaso en cuanto a reducir sus causas: Es coherente con la existencia de incertidumbres y con la marcha de las emisiones a la luz de los acuerdos internacionales.

Concluye que quizá el "secuestro" de carbono ya emitido no sea una mala opción. la concentración de dióxido de carbono por sólo 1,4.

El desastre en nuestras sociedades nunca vino de un hecho que las arruinara, sino de la construcción que las sustenta.
Los que menos tienen son físicamente más vulnerables y menos resilientes frente a catástrofes. Pese a que tanto las de origen natural como antrópico suelen golpear aleatoriamente, es sobre estos grupos que se debe trabajar más en la prevención y ayuda para la recuperación. los más lógicos para países con bajos niveles de emisión 
Tabla 1. Continuación.

Table 1. Continuation.

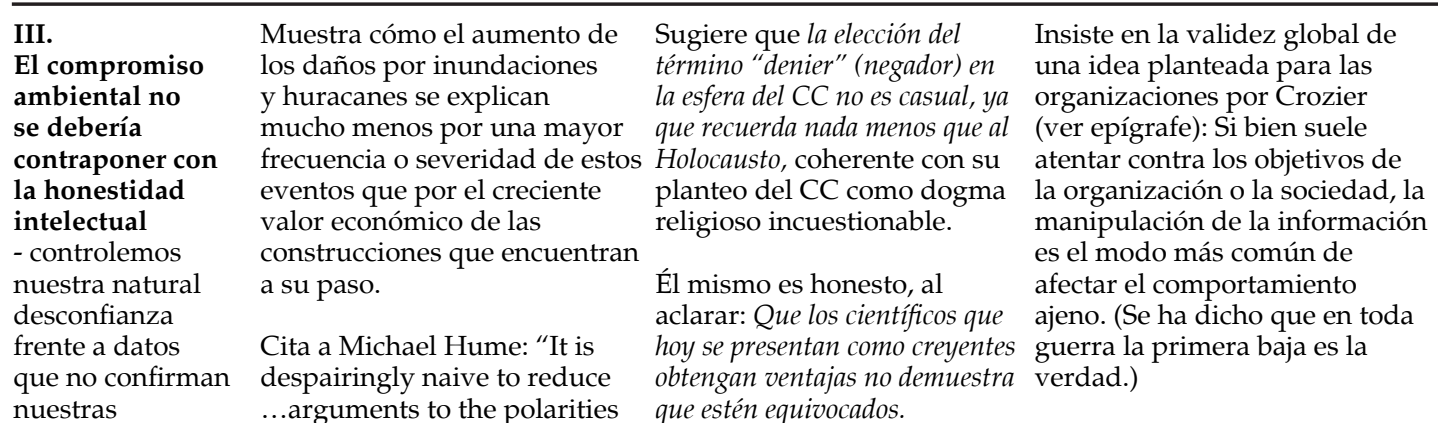

....arguments to the polariti

of "belief" or "scepticism"

...something much more

sophisticated ..."

IV.

Apelar sólo a la

responsabilidad individual es un error - no sólo es injusto sino que no está funcionando
Postula como una "Ley de Hierro" el conocido principio económico según el cual estamos dispuestos a aceptar costos o sacrificios inmediatos en vistas a beneficios futuros... pero sólo hasta cierto punto.

Anécdota: en una reunión del G8 hubo en el mismo día una sesión sobre cómo reducir el precio de los combustibles para potenciar la economía y otra, luego de un coqueto almuerzo, sobre cómo aumentar el precio para desalentar su uso.

El mundo necesita más energía barata - los que tienen que usar menos y pagar más son los ricos.
La lucha justa contra el CC ha conseguido ese status de las causas nobles que ya nadie puede cuestionar... que no dejan la posibilidad del desacuerdo. Son... el modo en que ... sectores con poder le hacen creer al resto que sus problemas [los de ellos] son [de todos]... la más burda y eficiente de las trampas..."

Comentario sobre la frase del Global Humanitarian Forum: “...para las poblaciones más pobres del mundo... el CC es un peso adicional insoportable ${ }^{\prime \prime} ;$ Lo auténticamente insoportable es no comer!
El llamado a la responsabilidad es coherente con la

"desregulación", i.e., el abandono del estado de muchas de sus obligaciones tradicionales y el aliento a la solución individual de problemas ante los que nos sentimos ignorantes e impotentes. Somos individuos por decreto.

Parte de esa "tercerización" se explica por la claudicación de los estados ("la política, que se ha vuelto local") frente a los poderes cada vez más globales.
Más aun: aunque pueda resultar indigesto para algunos, parece más que razonable que se canalice parte de los recursos de investigación en proyectosde remediación o ingeniería climática ("geoengineering"), tales como el secuestro de carbono y la modificación deliberada a gran escala de las propiedades de absorción de radiación de la atmósfera. Las objeciones a este tipo de enfoques pueden provenir de lo que Daniel Sarewitz llamó el Dilema del Progresista (Fernández 2014): si creemos que la causa de un problema ambiental está en una falla ética, parece insatisfactorio solucionarlo a través de una vía técnica o legal en lugar de hacerlo a través de cambios de comportamiento. Sin embargo, como veremos más adelante, está claro que la apelación a la "toma de conciencia" individual no es por sí sola una vía razonable ni efectiva.

\section{¿Honestidad intelectual vs. COMPROMISO AMBIENTAL?}

Si por un momento imaginamos que contamos con información certera, incluso perfecta, sobre un tema ambiental, y que la comunicamos de forma adecuada, ni siquiera así el camino a tomar es siempre claro. Tanto Pielke en su anterior libro, The Honest Broker (2007), como Sarewitz (2004) argumentaron que más información puede llevar a más confusión, o por lo menos a demorar las decisiones. Esto es así porque en la mayoría de los temas humanos, no sólo los ambientales, las preferencias, intereses y valores hacen que distintas personas y grupos le demos distinto peso a los costos y beneficios de cada decisión. En un artículo reciente (Fernández 2014) señalé que esto, tan fácilmente entendible, se contrapone con la creencia 
generalizada - y casi siempre tácita- de que más ciencia se traduce automáticamente en cursos más o menos obvios de acción en los temas ambientales. Aquí quiero enfatizar una contracara de ese error: interpretar como errónea o malintencionada toda información que se contraponga a la que derivaría en un curso de acción que nos parece correcto (falacia "ad consequentiam").

El trabajo del propio Pielke sobre catástrofes climáticas resumido en la Tabla I (fila III) provee un buen ejemplo. Su conclusión no es que el cambio climático no producirá un aumento en la frecuencia o en la severidad de los huracanes y las inundaciones, y ni siquiera que el aumento todavía no se ha producido. Simplemente, lo que este autor postula, y deja abierto al escrutinio de sus pares, es que dada la variabilidad de los datos y nuestro conocimiento de sus determinantes, no es posible detectar una señal de ese tipo (¿todavía?). En un debate bien intencionado y suficientemente profundo, no detectar tal tipo de señal no debería significar hacerle el juego a quienes se oponen a toda acción frente al cambio climático. Sin embargo, por este tipo de publicaciones Pielke ha sido acusado de negador ("denier") o no-creyente en el cambio climático. Caparrós, el menos científico de los tres autores, es el que mejor nos recuerda que un planteo así es opuesto al proceso científico, que no debería admitir certezas dogmáticas ni cerrar la puerta al sano escepticismo crítico (Tabla 1, filas III-IV).

La película de Al Gore llamó al cambio climático "Una Verdad Incómoda" (An Unconvenient Truth, 2006), y el libro de Pielke contiene varios mensajes que son incómodos por lo menos para tres grupos.

A) Los climatólogos y demás científicos: porque dice que no hace falta más ciencia para convencerse ni convencer de que los cambios son de origen antrópico, ya que el consenso científico y la convicción de la opinión pública son más que suficientes (lo que no quiere decir que Pielke o yo opinemos que no hace falta más ciencia: que sea insuficiente para convencer no quiere decir que sea innecesaria; todo lo contrario, es imprescindible).

B) Los activistas del cambio climático: porque los acusa de usar de forma selectiva la ciencia para argumentar en favor de su posición (como ya lo hizo para los lobistas encubiertos en general en su libro anterior [Pielke 2007].
Esto, además, no sería necesario ya que, como se dijo, la opinión pública está en su mayoría convencida. Sin embargo, creo que comete un error al llamar a ese apoyo popular "political will").

C) El ciudadano común: porque le dice que los cambios atmosféricos son inevitables y que, por ahora, a excepción quizás del secuestro de carbono, no hay ninguna tecnología en vista que por sí sola pueda atenuar el impacto, y que mientras sigan compitiendo los temas ambientales con el desarrollo económico tradicional, siempre ganará éste (lo que llama la Ley de Hierro de la política ambiental).

Nótese que Pielke puede ser acusado de enemigo de la causa ambiental leyendo selectivamente el texto de esos mensajes, en particular A) y B), por dar información que "al otro bando" le puede resultar útil en una batalla que no admite dudas ni grises, pero la falsedad de la acusación de negador es obvia leyendo cuidadosamente A) y C).

\section{RESPONSABILIDAD INDIVIDUAL Y DESIGUALDAD GLOBAL}

Para despejar cualquier duda acerca de las inaceptables desigualdades sociales entre continentes y países basta una mirada al mapa Wealth \& Health of Nations, publicado en www.gapminder.org, en particular notando la distancia entre puntos para los dos indicadores allí presentados (PBI per cápita y expectativa de vida al nacer) si se seleccionan escalas lineales y no logarítmicas. En cuanto al acceso a los alimentos, los servicios de salud y la educación, no existe un planeta, sino por lo menos dos. Es más: las fronteras entre esos dos mundos no coinciden con los límites políticos de los mapas, ya que las desigualdades dentro de cada país son tanto o más grandes que entre países. Bauman lo expresa de forma muy lúcida: las sociedades actuales son sociedades de consumidores, y por lo tanto, los materialmente menos favorecidos quedan excluidos (Tabla 1, fila II). Se los llama "marginales" porque no pertenecen a la sociedad dominante, sólo viven en su periferia (muchas veces, incluso, físicamente) (Caparrós dice que Niamey, la capital de Níger, parece toda un suburbio del segundo cordón: es puro margen). En particular, estos grupos son vulnerables a catástrofes como terremotos, inundaciones y 
huracanes, que aunque no sean selectivos por naturaleza, sí lo son en sus efectos.

Bauman destaca lo dicho por un líder local poco después de que New Orleans fuera devastada por el huracán Katrina en el año 2005: los más afectados fueron los pobres, es decir los negros ("poor, black people"). Esto no contradice lo dicho más arriba acerca de los efectos económicos crecientes de las catástrofes: en ese sentido, con el huracán, los ricos tenían más que perder, pero muchos pobres que no pudieron evacuarse perdieron sus vidas. El terremoto en Haití (2010) es otro ejemplo reciente. Caparrós le dedica a Katrina un capítulo entero, y concluye de modo similar al que lo hizo J.J. Rousseau sobre los efectos del terremoto, el incendio y el maremoto que arrasaron casi simultánemente Lisboa en 1755: el cambio climático puede traer problemas nuevos, pero es más probable que sólo agrave, o por lo menos exponga, los muy serios ya existentes (Tabla I, fila II). Como en los ejemplos más cercanos a nosotros (en los que el lector podrá estar pensando), las causas pueden tener componentes globales, pero los efectos son locales, y los más afectados siempre se parecen.

Para profundizar en esto tenemos que descartar una falacia, a la que propongo llamemos la "Trampa de los Promedios": tratándose de estándares de vida, los promedios son abstracciones que oscurecen desigualdades enormes, por ejemplo, en consumo y salud. Coincido plenamente con Bauman, quien va más allá de la usual crítica al producto bruto interno (PBI) per cápita como indicador de supuesto bienestar: independientemente del índice elegido, lo preocupante es que el foco esté en el valor de su promedio, como si la desigualdad no fuese algo que importe. Pielke pregunta: si cuando discutimos opciones de mitigación de emisiones sólo miramos el promedio: ¿qué tenemos para decirles a los cientos de millones de hogares sin electricidad? (20\% de la población mundial) ¿que su consumo de energía debe disminuir?

La última lección de la lista (ver Introducción) postula que apelar a la responsabilidad individual no sólo es injusto, sino que además en la práctica ha mostrado ser ineficaz. Esto es así porque el uso de los recursos naturales determina en muchos casos una competencia entre el cuidado del ambiente y el desarrollo económico, que Pielke resume en su ya mencionada Ley de Hierro, según la cual los beneficios a largo plazo son opacados por las ganancias y costos a corto plazo. Con resultados de encuestas, confirma que la gente está dispuesta a hacer sacrificios monetarios a favor del ambiente, pero sólo hasta cierto punto. Un área de clara fricción es el uso de energía, que ha venido aumentado desde hace un siglo por encima del crecimiento poblacional y se espera lo siga haciendo durante las próximas décadas a una velocidad de entre el 1 y $2 \%$ anual.

En este punto es útil incorporar al análisis la ecuación de Yoichi Kaya (Waggoner \& Ausubel 2002), que separa los impactos del uso de energía per cápita en dos componentes que toman en cuenta la variación de fuentes y eficiencias: la intensidad energética (IE, o consumo energético por unidad de PBI) y su intensidad de carbono (IC, emisiones por unidad de consumo energético). El producto IE x IC es la intensidad de carbono de la economía. Representa las emisiones de GEI por unidad de PBI y es semejante al término tecnológico en la clásica ecuación de impacto (I) de Ehrlich \& Holdren (1971):

$$
\mathrm{I}=\mathrm{P} \times \mathrm{C} \times \mathrm{T}
$$

en donde $\mathrm{P}=$ población, $\mathrm{C}=$ consumo $\mathrm{y}$ $\mathrm{T}=$ tecnología. Puesto en palabras: para reducir las emisiones deberíamos planificar un planeta con menos gente, con menos niveles de consumo promedio, o trabajar en las tecnologías, tanto en aquellas que apunten a una eficiencia mayor en el uso de las fuentes energéticas como en las que se basen sobre fuentes con menos emisiones. Las esperanzas están puestas más en los últimos términos de la ecuación que en el primero (aunque la ecuación ha sido criticada por poner el foco en el crecimiento poblacional; e.g. Barker 2009). Pero Pielke nos da dos malas noticias: que hay techos para las eficiencias de las tecnologías actuales y que no hay a la vista otras que puedan cambiar radicalmente el panorama.

Por otro lado, como la oferta de energía es mayormente fósil (y por lo tanto no renovable), también hay motivos noclimáticos para "descarbonizar" la economía. De hecho, hay una buena noticia: la economía mundial ya está en franca descarbonización, habiendo pasado en las últimas tres décadas de alrededor de una tonelada de $\mathrm{CO}_{2}$ por cada mil dólares de PBI a aproximadamente 
la mitad, y en algunos países aún menos (llama la atención lo poco que estas tendencias tienen que ver con la distribución temporal y geográfica de los compromisos asumidos en relación al Protocolo de Kioto). Pielke dedica una buena parte del libro a mostrar que lamentablemente, bajo un amplio rango de escenarios tecnológicos y económicos plausibles, esa tendencia no será de ningún modo suficiente para reducir las emisiones de GEI. Esto significa que tampoco será suficiente para estabilizar su concentración atmosférica (para el dióxido de carbono, ni siquiera en 550 ppm; es decir, el doble de la concentración pre-industrial [muy usado en las simulaciones climáticas, pero inaceptablemente alto para muchos]). Sus cálculos coinciden con estudios anteriores: aun para un objetivo tan modesto debería inaugurarse cerca de una central nuclear por día. Como ya lo advertían Ehrlich \& Holdren (1971), muchas de las opciones que se nos presentan son difíciles porque determinan que tengamos que elegir entre diferentes tipos de riesgos que no son directamente comparables.

\section{CONCLUSIÓN: TEORÍAS CONSPIRATIVAS VS. PROPUESTAS}

En la última página de su libro, Caparrós dice que la enorme atención dada al cambio climático presenta ventajas económicas para el norte, pero sobre todo ideológicas. Las ventajas económicas incluirían el retraso de la industrialización del sur y las ganancias derivadas de los bonos de carbono y otras iniciativas verdes. Las ventajas ideológicas consistirían en reforzar lo peor del conformismo conservador: todo cambio es peligroso porque puede hacernos perder lo que tenemos, enfatizando las ventajas del "statu quo", que - obviamente- no son ventajas para todos (aparentemente, las expresiones "conservacionista" y "cambio global" fueron sugeridas por un consultor al presidente George W. Bush para reemplazar las de "ambientalista" y "calentamiento global", que suenan demasiado radicales y catastróficas). En 1992, Caparrós creó el término "ecololó" para ridiculizar el ecologismo acrítico, y en su libro lo usa para su mensaje más antipático: ser ecololó es una forma conservadora de ser "cool".

El grado en que podamos estar de acuerdo con estas interpretaciones quizás dependa de nuestra tendencia a creer en las teorías conspirativas o, dicho de un modo más académico, a sobreestimar el poder y la perversidad de los adversarios (lo que es común: Sabatier \& Weible 2007). Sin embargo, en mi opinión, las intenciones no son tan importantes. Para las víctimas de los "daños colaterales" (ver reseña Bauman en Tabla 1) es casi irrelevante si algo fue hecho a propósito o no, ya que lo que importa es la acción o inacción en sí. Ahora bien, dado que las cuatro lecciones resumidas en la Introducción son de carácter negativo, ¿cómo empezar a pensar en un camino que nos libre de la lógica desarrollo económico vs. cuidado del ambiente? Basándome en el escenario de inequidad resaltado más arriba (que hay "dos planetas", uno de ricos y otro de pobres), acá voy a esbozar dos caminos, ambos aplicables en principio en general, aunque el segundo más relevante para el nivel nacional. Sin caer en el simplismo de quelas soluciones a problemas tan complejos como estos sólo requieren "voluntad política", quiero señalar que las vías académicas y democráticas para la discusión están abiertas, y hay mucha experiencia acumulada al respecto (Fernández 2014).

La primera propuesta se centra en la lógica del mercado y reconoce que los conceptos comerciales de "buenas prácticas" y, en particular, el de "huella de carbono" (GEI emitidos por efecto directo o indirecto de la producción y consumo de un bien) pueden tener una influencia inmediata deseable sobre la demanda de bienes y servicios económicos, y por lo tanto a mediano plazo sobre el uso de los recursos en los que se basan. Teniendo en cuenta que la demanda más alta proviene de los sectores de mayor poder adquisitivo, que son los que potencialmente tienen acceso a la mejor información, este camino parece útil y natural. Sin embargo, Jobbágy (2014) ha criticado recientemente el concepto de huellas, al menos aquellas derivadas de metodologías "enlatadas", por su falta de atención al contexto (su ejemplo es que una huella hídrica alta en un producto del agro puede representar una ventaja en una situación de anegamiento al eliminar el exceso de agua del ecosistema). Por otro lado, una gran ventaja de las huellas es que proveen información simple sobre la que el consumidor puede basar su decisión (tal como ahora podemos hacerlo, por ejemplo, con la eficiencia de consumo de energía y agua de algunos electrodomésticos). Por eso propongo ir un paso más allá y sugerir que, además de una correcta normativa y estricto control de su 
cálculo y contexto, incluyendo todo el ciclo de vida del producto, las metodologías de huellas se amplíen para evaluar, además de los GEI, también los impactos que se consideren importantes para cada actividad, los que según el contexto pueden ser considerados como negativos (e.g., huella de C) o positivos (e.g., "huella de trabajo", medida en horashombre).

Los riesgos del mal uso de las huellas son por lo menos dos, y ambos ya se han manifestado. Un riesgo, del lado de los competidores, es que las sobreestimen y usen como barreras para-arancelarias, como históricamente se ha hecho para productos del agro con problemas sanitarios como la aftosa y los residuos de sustancias tóxicas en alimentos. El otro riesgo, del lado de los oferentes, se deriva de lo fácil que resulta para las empresas abusarse, subestimándolas si no hay estudios de base y controles adecuados. Esta última sería una versión sofisticada del "maquillaje (o barniz) verde", cubriendo la falta de verdadero esfuerzo e inversión dirigidos a mejorar las prácticas ambientales, reducir los desechos (incluyendo aumentos en la vida útil del producto vs. su obsolescencia programada), etc. A esto se lo conoce hoy como "greenwashing", pero es una idea que ya tiene décadas, y que en su momento se llamó "eco-pornografía" (un nombre muy revelador de algo bueno en su origen pero transformado en un mero producto comercial). Responsabilidad Social Empresaria es otra expresión, más amplia, usada en este contexto junto con Buenas Prácticas y que, a fuerza de ser bastardeada, ha ido quedando vacía de significado (y aun con connotaciones negativas). Si no ponemos suficiente énfasis en educar a los consumidores sobre estos riesgos, alentaremos el ecololismo y obstaculizaremos los avances.

La segunda propuesta también se relaciona con la inequidad, en particular con la Trampa de los Promedios enunciada en la sección de Responsabilidad Individual. Desde hace dos décadas, hay una idea de "Contracción y Convergencia" según la cual las emisiones antrópicas se podrían reducir hasta un nivel aceptable (contracción) a través de una homogeneización (convergencia) de las emisiones per cápita de los distintos países. Naturalmente, esto no ha avanzado en los foros internacionales ya que requeriría reducciones en las emisiones de los países más prósperos.
Por otro lado, aunque se reconoce que el sobreconsumo coexiste con el subconsumo, me parece que hay una tendencia, por lo menos desde el sur, a pensar que los ricos son siempre los otros. Caparrós cuenta que una señora nigeriana le dijo que es fácil reconocer a los ricos porque son los únicos gordos, a lo que él contestó que estaba gordo y sin embargo no era rico, provocando la lógica pregunta de la mujer "¿para quién?".

Según los datos del Banco Mundial (accesibles desde www.gapminder.org), la emisión actual deGEI per cápita para Argentina es equivalente a $4.5 \mathrm{t}$ de $\mathrm{CO}_{2}$ /año, un valor similar a los de China y México, superior al 1.5 de la India y de Perú, muy por debajo de las 15-20 de Australia, Canadá y EEUU o las 10 de Alemania y Rusia, pero no muy diferente al promedio mundial, que está apenas por encima de 5 (Francia y Suiza tienen 5-6). La intensidad energética de nuestra economía (ver definición más arriba) también es llamativamente similar al promedio mundial. Glenn Firebaugh (2008) encontró que las desigualdades de ingresos promedio per cápita entre países han tendido a disminuir desde fines del siglo $X X$, después de haber crecido durante mucho tiempo; las diferencias dentro de cada país no han aumentado a la misma velocidad. Teniendo en cuenta esa distinción, y que tomar decisiones a nivel del propio país debiera ser más fácil que convencer a otros de que lo hagan en los suyos, propongo que el planteo de Contracción y Convergencia se aplique a nivel nacional, concibiendo aumentos en las emisiones por parte de los grupos con menores niveles de ingresos, más que compensados por la reducción de emisiones por parte de los grupos con mayor poder adquisitivo. Aunque la situación ha tendido a mejorar en la última década, América Latina sigue teniendo elevadas desigualdades a nivel nacional, con un promedio de $47 \%$ de los ingresos totales yendo al quintil más rico, y menos del 6\% al quintil más pobre (CEPAL 2014).

La inequidad no es nueva, pero eso nunca fue una buena excusa para la inacción y tampoco lo es bajo este nuevo contexto que incluye al cambio climático (sobre todo porque gracias a los avances tecnológicos y al conocimiento acumulado nunca tuvimos tantos medios para eliminar la pobreza como hasta ahora). Claramente, la idea de contribuir de manera activa a un buen cálculo de huellas, incorporando no sólo los GEI sino otros 
indicadores socioambientales importantes, representa actuar más "a favor de la corriente" que la de aumentar la equidad nacional o regional. Además, la primera apela más a nosotros como investigadores, profesionales y especialistas (de hecho, puede representar una interesante fuente de trabajo), mientras que la segunda es más incómoda ya que apela a nuestra conciencia ciudadana. Dos décadas después de la Cumbre de la Tierra en Río de Janeiro, va quedando claro en la arena de los organismos internacionales que no hay modo de aproximarse al cumplimento de los Objetivos de Desarrollo Sustentable de las Naciones Unidas sin una atención simultánea y sinérgica a los Objetivos del Milenio, tales como erradicar el hambre y mejorar la salud y la educación (Griggs et al. 2013). A mi juicio, lo expuesto hasta aquí muestra que estaríamos listos para intentar hacerlo, no sólo por ser necesario y justo, sino porque hay vías para empezar estas discusiones a nivel nacional y porque la experiencia reciente deja varias lecciones muy claras sobre lo que no conviene hacer.

Agradecimientos: El manuscrito se benefició con críticas y sugerencias de I. Bartomeus, A. Bisigato, C. DiBella, J. Gowda, E. Jobbágy, M. Oesterheld, M. Semmartin y un revisor anónimo. Financiamiento: UBACyT20020130100873BA.

\section{BibLIOGRAFíA}

BARKer M. 2009. Environmental Populationism, a dangerous obsession. Swans Commentary. Agosto 10.
Bauman, Z. 2011. Daños Colaterales. FCE, Buenos Aires.

Caparrós, M. 2010. Contra el Cambio; un Hiperviaje al Apocalipsis Climático. Anagrama, Buenos Aires.

CEPAL. 2014. Panorama Social de América Latina. Naciones Unidas.

EHRLICH, PR \& JP HOLDREN. 1971. Impact of population growth. Science, 171:1212-1217.

FERNÁNDEZ, RJ. 2014. Decálogo del ambientalismo estéril. Ecología Austral, 24:256-364.

Firebaugh, G. 2008. The New Geography of Global Income Inequality. Harvard Univ. Press.

GRIGGS, D; M STAFFORD-SMITH; O GAFFNEY; I ROCKSTRÖM; MC ÖHmAN; ET AL. 2013. Sustainable development goals for people and planet. Nature, 495:305-307.

Ingram, H; AL Schneider \& P DeLeón. 2007. Social construction and policy design. Pp. 93-128 en: Sabatier, PA (ed.). Theories of the Policy Process, $2^{\mathrm{a}}$ ed. Westview.

JobBÁgY, EG. 2014. Del mito de la sustentabilidad a la realidad del cambio y el compromiso ambiental. Congreso Tecnológico CREA. Disponible en youtube.

PACALA S \& R Socolow. 2004. Stabilization wedges: solving the climate problem for the next 50 years with current technologies. Science, 305:968-972.

PIelKe, RA JR. 2007. The Honest Broker; Making Sense of Science in Policy and Politics. Cambridge Univ. Press.

PIElKe, RA JR. 2010. The Climate Fix: What Scientists and Politicians Won't Tell You About Global Warming. Basic Books. Pp. 272.

SABATIER, PA \& CM Weible. 2007. The advocacy coalition framework: Innovations and clarifications. Pp 189-220 en: Sabatier, PA (ed.). Theories of the Policy Process, $2^{\mathrm{a}}$ ed. Westview.

SAREWITZ, D. 2004. How science makes environmental controversies worse. Environmental Science E Policy, 7:385-403.

WAggoner, PE \& JH Ausubel. 2002. A framework for sustainability science: A renovated IPAT identity. PNAS, 99:7860-7865. 